Check for updates

Cite this: Chem. Sci., 2019, 10, 447

๑ All publication charges for this article have been paid for by the Royal Society of Chemistry

Received 26th September 2018

Accepted 11th October 2018

DOI: $10.1039 / \mathrm{c} 8 \mathrm{sc} 04272 a$

rsc.li/chemical-science

\section{Bisulfite-free, single base-resolution analysis of 5-hydroxymethylcytosine in genomic DNA by chemical-mediated mismatch $\dagger$}

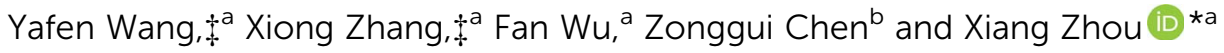

5-Hydroxymethylcytosine $(5 \mathrm{hmC})$ is known as one of the vital players in nuclear reprogramming and the process of active DNA demethylation. Although the development of whole-genome sequencing methods for modified cytosine bases has burgeoned, the easily operated gene-specific loci detection of $5 \mathrm{hmC}$ has rarely been reported. Herein, we present a single-base resolution approach, i.e., chemical-assisted mismatch sequencing (CAM-Seq), which, when combined with traditional oxidation and chemical labeling mediation, can be used for mapping $5 \mathrm{hmC}$ at base resolution. We employ chemical oxidation to transform $5 \mathrm{hmC}$ to 5 -formylcytosine $(5 \mathrm{fC})$, followed by chemical labeling to induce $\mathrm{C}$-to-T base changes owing to the fact that the loss of the exocyclic 4-amino group of labeled $5 \mathrm{fC}$ leads to $\mathrm{C}$ to $\mathrm{T}$ conversion and subsequent pairing with adenosine (A) in PCR. The feasibility of CAM-Seq is demonstrated in different synthetic oligonucleotide models as well as in part of the genome of $5 \mathrm{hmC}$-rich mouse embryonic stem cells (mESCs). Moreover, the gene fragment containing $5 \mathrm{hmC}$ can be easily biotinylated after oxidation, showing high enrichment efficiency. Our method has the potential capability to map $5 \mathrm{hmC}$ in genomic DNA and thus will contribute to promoting the understanding of the epigenetic modification of $5 \mathrm{hmC}$.

\section{Introduction}

Chemical modifications of DNA bases can profoundly influence various cellular processes, and several epigenetic modifications have been found in a variety of mammalian tissues and organisms. ${ }^{1,2}$-Hydroxymethylcytosine $(5 \mathrm{hmC})$ was discovered as an epigenetic mark, and it is produced via an active DNA demethylation process which involves the iterative oxidation of 5 -methylcytosine $(5 \mathrm{mC})$ driven by ten-eleven translocation (TET) family proteins. ${ }^{3-7}$ Of particular interest is the fact that $5 \mathrm{hmC}$ has been found in embryonic stem cells ${ }^{6,8-11}$ and brain tissue, ${ }^{12-15}$ and it affects gene expression through inhibition binding of $5 \mathrm{mC}$ binding proteins or recruiting specific binding proteins of $5 \mathrm{hmC} .{ }^{16,17}$ The relative abundance of $5 \mathrm{hmC}$ in different tissues may be due to its cell type specificity ${ }^{18,19}$ and $5 \mathrm{hmC}$ is associated with various diseases such as cancers. ${ }^{20-23}$ Thus, in addition to being an intermediate of active DNA demethylation, $5 \mathrm{hmC}$ is involved in regulatory functions in essential biological processes. ${ }^{24}$

${ }^{a}$ College of Chemistry and Molecular Sciences, Key Laboratory of Biomedical Polymers of Ministry of Education, The Institute for Advanced Studies, Hubei Province Key Laboratory of Allergy and Immunology, Wuhan University, Wuhan, Hubei, 430072, P. R. China. E-mail: xzhou@whu.edu.cn; Fax: +86-27-68756663; Tel: +86-2768756663

${ }^{b}$ College of Life Science, Wuhan University, Wuhan, Hubei, 430072, P. R. China

$\dagger$ Electronic supplementary information (ESI) available. See DOI: $10.1039 / \mathrm{c} 8 \mathrm{sc} 04272 \mathrm{a}$

\$ These authors contributed equally.
To date, an ample variety of methods have been developed to detect $5 \mathrm{hmC}$. For the whole genome-wide mapping of $5 \mathrm{hmC}$, several strategies have been established, such as hydroxymethylated DNA immunoprecipitation (hMeDIP) assisted by antibodies $^{25}$ and selective chemical labeling with streptavidin beads after the glucosylation of $5 \mathrm{hmC}$ and then biotinylation. ${ }^{26}$ Although these methods can solve the problem of the presence of $5 \mathrm{hmC}$ in short genomic regions, the resolution depends on the fragment size of the genomic DNA, because of which the precise sites cannot be identified. A method for single nucleotide resolution of $5 \mathrm{hmC}$ will enable the identification of individual modifications on the genome-wide scale and it will help us to deeply understand the role $5 \mathrm{hmC}$ plays in epigenetics. For example, to determine $5 \mathrm{hmC}$ distribution with respect to transcription factor binding sites, strategies based on the bisulfite treatment of DNA are developed. $5 \mathrm{hmC}$ can be protected by glucosylation, followed by Tet-assisted bisulfite sequencing (TAB-Seq), which can realize the base-resolution analysis of $5 \mathrm{hmC}$ in the mammalian genome. ${ }^{27}$ The previous literature reported that $\mathrm{KRuO}_{4}$ could selectively oxidize $5 \mathrm{hmC}$ to 5 -formylcytosine (5fC) in high yield, and $5 \mathrm{fC}$ is deaminated after bisulfite treatment and therefore sequenced as thymine (T) ${ }^{28}$ All these excellent studies provide diversified methods to uncover the uncharted territory of $5 \mathrm{hmC}$. It is notable that these methods all rely on harsh bisulfite-mediated conversion, which often causes further DNA degradation. ${ }^{29,30}$

Herein, we describe a bisulfite-free method for the singlebase resolution sequencing of $5 \mathrm{hmC}$ and demonstrate its 
(a)

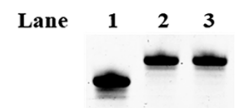

(b)

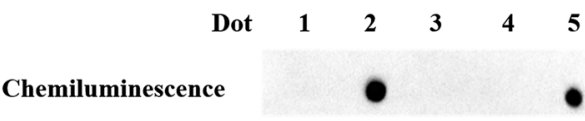

Methylene Blue

Fig. 1 Polyacrylamide gel electrophoresis analysis and dot-blot assay (a) Polyacrylamide gel electrophoresis analysis of the protected $5 \mathrm{fC}$. Lane 1: ODN-5fC without treatment; lane 2: ODN-5fC protected with hydroxylamine; lane 3: ODN-5fC protected with hydroxylamine and then treated with azi-BP. (b) Dot-blot assay of the streptavidin-HRP detection of oxidized $5 \mathrm{hmC}$ labeled with azi-BP and DBCO-PEG4biotin. Dot 1: 80 bp ds ODN-5hmC without treatment; dot 2: 80 bp ds ODN-5hmC ligated with an adapter and oxidized by $\mathrm{KRuO}_{4}$ and then labeled with azi-BP and DBCO-PEG4-biotin; dot 3: 80 bp ds ODN$5 \mathrm{fC}$; dot 4: $80 \mathrm{bp}$ ds ODN-5fC protected with hydroxylamine and then incubated with azi-BP and DBCO-PEG4-biotin; dot 5: 80 bp ds ODN$5 f C$ treated with azi-BP and DBCO-PEG4-biotin. Only the biotin labeled DNA can produce a dot. And after methylene blue incubation, we can verify the existence of DNA for every dot.

feasibility in genomic DNA sequencing (Fig. 1). Malononitrile and an azido derivative of 1,3-indandione were used for labeling $5 \mathrm{fC}$, which realized the identification $5 \mathrm{fC}$ without bisulfite treatment at single-base resolution by CLEVER-seq ${ }^{31}$ and the fCCET method, ${ }^{32}$ respectively. We previously reported some chemical molecules for the selective labeling of $5 \mathrm{fC},{ }^{33-35}$ and some of these chemical molecules can also realize the goal of single-base analysis of 5fC. For instance, our group reported that $5 \mathrm{fC}$ can be labeled with azi-BP ${ }^{34}$ (the structure of azi-BP is shown in Scheme 1), and the azide group of azi-BP-fC can react with DBCO-biotin reagents through a copper-free click reaction $^{26,36}$ The conceptual basis for the single-base sequencing of $5 \mathrm{hmC}$ involves chemical-assisted mismatch sequencing (CAM-

(a)

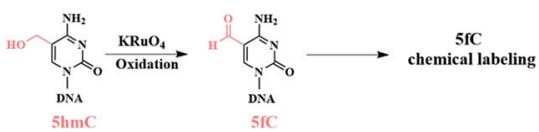

(b)

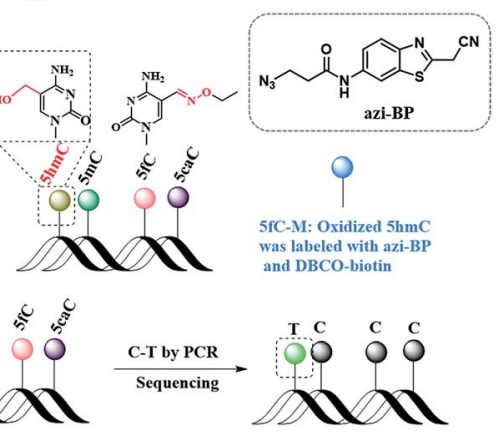

Scheme 1 A method for the single-base resolution sequencing of $5 \mathrm{hmC}$. (a) $5 \mathrm{hmC}$ is selectively oxidized to $5 \mathrm{fC}$ by $\mathrm{KRuO}_{4}$. (b) Schematic diagram of CAM-seq. First of all, $5 \mathrm{fC}$ is protected by hydroxylamine. Next, $5 \mathrm{hmC}$ is oxidized to $5 \mathrm{fC}$, and the oxidized product is labeled with azi-BP. Then labeled product is used for sequencing.
Seq). First, $5 \mathrm{hmC}$ was selectively oxidized to $5 \mathrm{fC}$ by $\mathrm{KRuO}_{4}$. Then $5 \mathrm{fC}$ was labeled with the chemical molecule previously reported by our group, namely, azi-BP. ${ }^{34}$ As mentioned in the reported literature, ${ }^{31,32,34}$ owing to the original $4^{\prime}$ amino group of $5 \mathrm{fC}$ participating in cyclization, which is no longer a competent proton donor for the canonical base pairing with guanine (G), matching with adenine (A) and misreading as thymidine (T) occurs during the PCR process for realizing the single-base resolution analysis of $5 \mathrm{hmC}$. Moreover, the click chemistry reaction to install a biotin tag can selectively enrich the $5 \mathrm{hmC}$ containing fragment. Thus, the design can easily identify $5 \mathrm{hmC}$ in a bisulfite-free manner.

\section{Results and discussion}

\section{Evaluating the protection of $\mathrm{ODN}-5 \mathrm{fC}$ with hydroxylamine}

To eliminate the influence of the original $5 \mathrm{fC}$ in the tested samples, hydroxylamine was used for protecting $5 \mathrm{fC}^{37}$ to prevent it from reacting with azi-BP. First, we verified that the protected 5fC could not react with azi-BP, and ODN-5fC was chosen for the test. As shown by denaturing polyacrylamide gel electrophoresis (PAGE) analysis (Fig. 1a), the retarded migration of ODN-5fC indicated that it was successfully protected by hydroxylamine. When the protected ODN-5fC was further incubated with azi-BP, no new band appeared in the gel. These results suggested that hydroxylamine could effectively protect $5 \mathrm{fC}$ from being labeled with azi-BP.

\section{Evaluating the reactivity of azi-BP with oxidized ODN-5hmC}

Next, we evaluated the reactivity of azi-BP towards the labeling of oxidized $5 \mathrm{hmC}$. Because the hydroxyl groups of both the $5^{\prime}$ and $3^{\prime}$ ends of DNA can be oxidized by $\mathrm{KRuO}_{4},{ }^{38}$ a universal nextgeneration sequencing (NGS) adapter bearing $5^{\prime}$-O-methyl groups and $3^{\prime}$-O-phosphate groups was used to alleviate potential interference from the oxidation of the hydroxyl groups on the ends of the DNA fragment. Double-stranded DNA containing $5 \mathrm{hmC}$ (E-DNA-hmC) was ligated with the 5'-O-methyl group and $3^{\prime}-O$-phosphate group modified adapters using the standard protocol, and then the purified adapter-ligated DNA samples were subjected to oxidization by $\mathrm{KRuO}_{4}$. After purification, the mixture was incubated with azi-BP and DBCO-biotin for the dot blot assay. The dot indicated that the oxidized $5 \mathrm{hmC}$ can be effectively labeled by azi-BP (Fig. $1 \mathrm{~b}$, dot 2), and the $5 \mathrm{fC}$ protected by hydroxylamine could not be further labeled with azi-BP (Fig. 1b, dot 4), which suggested that after being protected by hydroxylamine, the original $5 \mathrm{fC}$ could not affect the detection of $5 \mathrm{hmC}$.

\section{Sanger sequencing for single-base resolution analysis of $5 \mathrm{hmC}$ in synthesized DNA}

Encouraged by the result of the dot blot assay, we proceeded to perform CAM-Seq to analyze $5 \mathrm{hmC}$ at single-base resolution. As reported previously, ${ }^{34}$ azi-BP labeled $5 \mathrm{fC}$ generates a cyclic reaction, which leads to the loss of the 4-amino group of $5 \mathrm{fC}$ and thus the failure to pair with $\mathrm{G}$ in a canonical base pairing manner. The disabling of the proton donor by the original 4- 
amino group causes modified $5 \mathrm{hmC}$ to pair with A. As a proofof-concept, an $80 \mathrm{bp}$-ds DNA containing one site of $5 \mathrm{hmC}$ (seq1 ds-ODN-5hmC, ESI Table S1 $\dagger$ ) was oxidized and further labeled by azi-BP. After amplification by PCR with MightyAmp DNA polymerase, the products were further applied in single cloning analysis. The Sanger sequencing results showed that modified $5 \mathrm{hmC}$ is read as T during sequencing (Fig. $2 \mathrm{a}$ and b), indicating that the designed strategy can realize the singlebase resolution analysis of $5 \mathrm{hmC}$. To further prove the results of Sanger sequencing, the presence of $5 \mathrm{hmC}$ at seq- 1 ds-ODN-5hmC was confirmed by conventional bisulfite sequencing (Fig. 2c and d). Whether CAM-Seq can recognize multiple $5 \mathrm{hmC}$ sites simultaneously is vital to generalize its application in the genome owing to the fact that $5 \mathrm{hmC}$ may also be present continuous. A model DNA strand containing two $5 \mathrm{hmC}$ sites (seq-2 ds-ODN-5hmC, ESI Table S1†) was chosen for testing the feasibility. To our delight, the $\mathrm{C}$ to $\mathrm{T}$ conversions in $5 \mathrm{hmC}$ sites were all observed by Sanger sequencing, which showed that the sites of $5 \mathrm{hmC}$ can be accurately located by CAM-Seq (Fig. S1†).

\section{Sanger sequencing for the single-base resolution analysis of 5 hmC in genomic DNA from mESCs}

Encouraged by the above results, we then asked whether CAM-Seq could be applied to $5 \mathrm{hmC}$ detection in some specific genomic DNA regions. To this end, several specific regions from mESCs $^{39}$ reported to contain $5 \mathrm{hmC}$ were selected for the test. For example, the gene of PAX5 as a B cell transcription factor was chosen for the test. First, we extracted the genomic DNA from mESCs. Then the genomic DNA was incubated with hydroxylamine and subjected to oxidation as described by the protocol reported previously, ${ }^{28,40}$ followed by labeling with azi-BP and PCR. The PCR products were verified by agarose gel electrophoresis analysis (Fig. S2 $\dagger$ ). As measured by CAM-Seq, the precise loci of $5 \mathrm{hmC}$ in the tested regions can be identified. These results were further confirmed by conventional bisulfite sequencing (Fig. 3). And several other regions were also tested (Fig. S3†). Collectively, this design will be a potential approach for $5 \mathrm{hmC}$ detection in the genome.
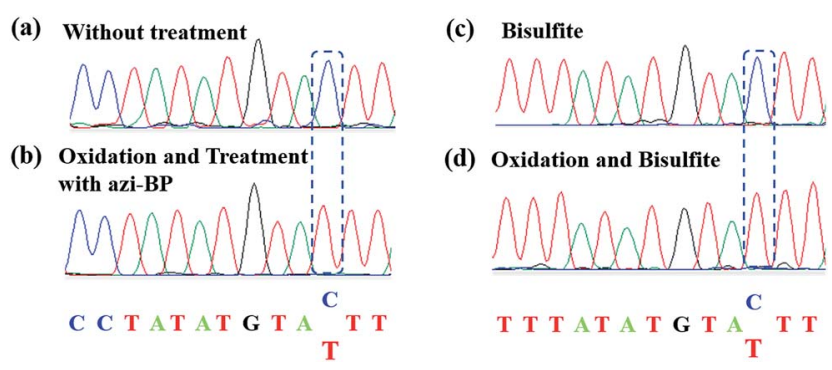

Fig. 2 Model ODN (seq-1 ds-ODN-5hmC) to verify the feasibility of the CAM-seq. method (a) The Sanger sequencing results of the original sequence. (b) The Sanger sequencing results of the model ODN by CAM-seq. (c) The sequencing results of bisulfite treatment. (d) The sequencing results of oxidation and bisulfite treatment.
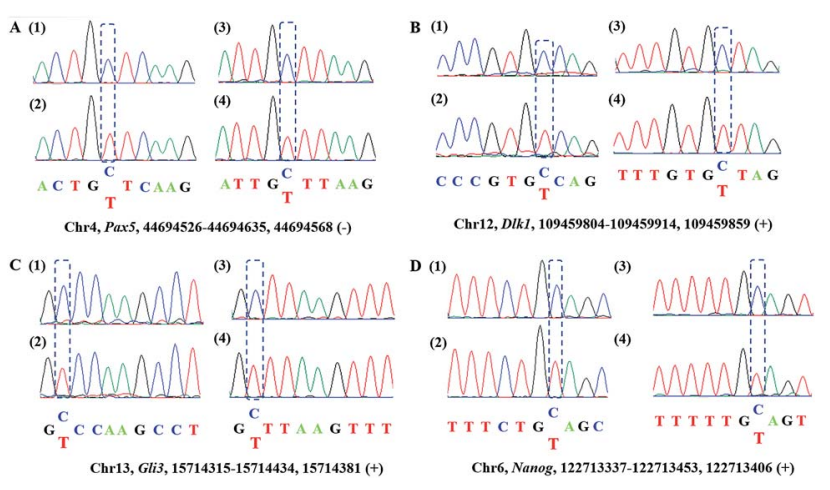

Fig. 3 Sanger sequencing of the genomic DNA from mouse ES cells. A represents the intron regions of Pax 5 in chr4; $B$ represents the gene of Dlk1 in chr12. C represents the gene of Gli3 in chr13; D represents the gene of Nanog in chr6. (1) Standard sequencing; (2) CAM-seq; (3) BSSeq; (4) Ox-BS-Seq.

\section{Illumina sequencing of synthesized DNA containing $5 \mathrm{hmC}$}

Whether CAM-Seq can be used for high-throughput sequencing is vital for the genome-wide analysis of $5 \mathrm{hmC}$ at single-base resolution. A synthetic oligonucleotide with one $5 \mathrm{hmC}$ at a defined position (seq-1 ds-ODN-5hmC) was applied in NGS; we also spiked in unmodified DNA (seq-1 ds-ODN-C, seq-1 ds-ODN$5 \mathrm{hmC}$ : seq-1 ds-ODN-C $=1: 10$ ) to increase the complexity of the system. The DNA without treatment was used as the control sample. First, the model DNA was ligated to the modified NGS adapter. Then the adapter ligated DNA sample was denatured in $\mathrm{NaOH}$ followed by oxidization with $\mathrm{KRuO}_{4}$. After labeling with azi-BP and DBCO-S-S-PEG 3 -biotin, a pull-down assay was carried out to enrich the labeled $5 \mathrm{hmC}$. The enriched sample was quantified using Qubit and then applied in the amplification with minor modifications. Briefly, the libraries were amplified using the MightyAMP DNA polymerase (Takara). These libraries were sequenced on a HiSeq X Ten platform in $150 \mathrm{bp}$ paired-end mode. As demonstrated by bioinformatics analysis, the NGS data showed significant C-to-T conversion. The ratio of $\mathrm{T}$ read is $\sim 88 \%$ (Fig. 4 ). It is worth mentioning that
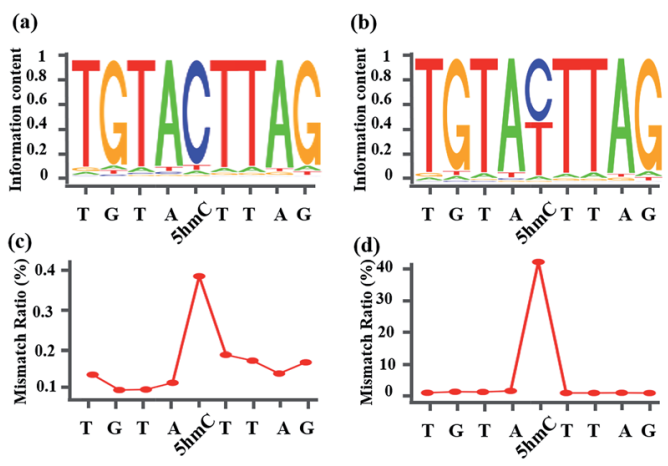

Fig. 4 Oxidized-chemical-labeling-induced C-to-T conversion of $5 \mathrm{hmC}$ in a double-stranded $5 \mathrm{hmC}$-containing spike-in sequence. (a) Sequence logo of the control sample, showing a low rate of C-to-T transition. (b) Sequence logo of the sample treated with CAM-Seq, showing a high rate of C-to-T transition. (c) Mismatch ratio of the control sample. (d) Mismatch ratio of the sample treated with CAM-Seq. 
the $\mathrm{C}$ read counts in the treated samples, which are comparable to the $\mathrm{T}$ read counts, come from the complementary strand of the 5 hmC containing sequence. These inspiring NGS results with single-base resolution encouraged us to implement this CAM-Seq for precise $5 \mathrm{hmC}$ mapping in the whole genome in the near future.

\section{Inhibition of DNA polymerase replication by DBCO-PEG4- biotin}

After modifications, the large group was added to the labeled 5 hmC, which may create a barrier against normal enzymatic reactions such as PCR. $80 \mathrm{bp}$ double-stranded DNA strands containing $5 \mathrm{hmC}$ and $5 \mathrm{fC}$ (E-DNA-hmC, DNA-fC, ESI Table S1 $\dagger$ ) were chosen for further study. These DNA strands were incubated with hydroxylamine and then subjected to oxidation. After purification, these samples were labeled with azi-BP and DBCO-S-S-PEG4-biotin. Taq DNA polymerase from a Hieff ${ }^{\mathrm{TM}}$ PCR SYBR ${ }^{\circledR}$ Green Master Mix was selected to test the effect of this huge additional group on the replication of labeled 5hmC. Quantitative PCR (qPCR) analysis was used to evaluate the polymerase activity. Ct value represents the number of cycles required to achieve the set fluorescence value. A larger Ct value indicates a less effective DNA template, which means that the replication process was hampered. As expected, the oxidized and chemically labeled 5hmC showed a higher Ct value than the untreated sample (Fig. 5, red line). Moreover, after being protected by hydroxylamine, the $5 \mathrm{fC}$ containing DNA could not affect the activity of DNA polymerase. The result is also consistent with the PAGE and dot blot analysis (Fig. 1) in that protected $5 \mathrm{fC}$ could not be further labeled with azi-BP. These results demonstrate that our design assisted by PCR amplification can detect a low content of $5 \mathrm{hmC}$ in a complex environment, and this encourages us to perform further detailed study.

\section{Enriching 5hmC-containing DNA fragments}

In addition to the advantage of $5 \mathrm{hmC}$ single-base resolution analysis, the azi-BP can be biotinylated to provide another application for enriching DNA fragments bearing oxidized 5 hmC. To evaluate the enrichment efficiency, three $80 \mathrm{bp}$ dsDNA strands (E-DNA-C, E-DNA-hmC, E-DNA-fC, ESI Table $\mathrm{S} 1 \dagger)$ were used as the enrichment models. The process of enrichment efficiency analysis is shown in Fig. 6a. First, these model DNA strands were mixed in equal moles, and incubated

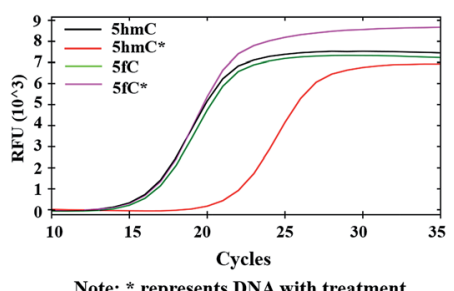

Fig. 5 qPCR analysis of $5 \mathrm{hmC}$. Labeled $5 \mathrm{hmC}$ inhibits the amplification activity of Taq DNA polymerase.
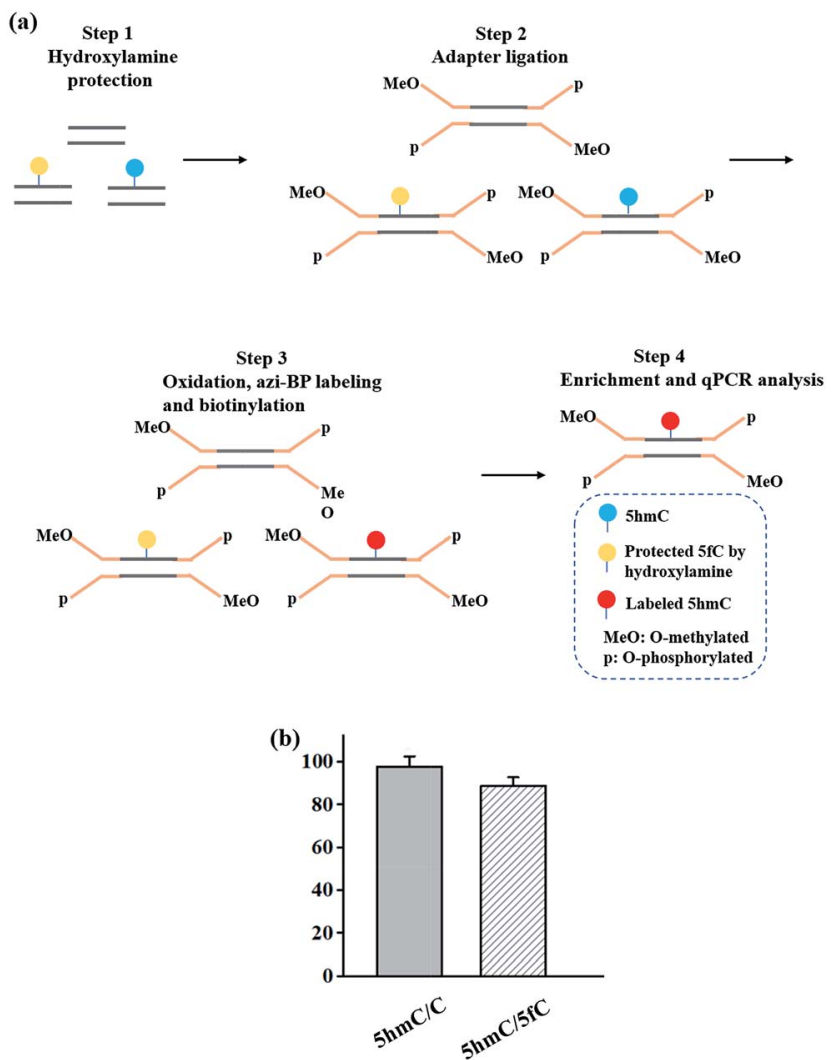

Fig. 6 Enrichment of 5hmC. (a) Schematic of the enrichment efficiency analysis. (b) Extent of enrichment of $5 \mathrm{hmC}$ in double-stranded DNA towards $C$ and $5 f C$ ODN sequences.

with hydroxylamine to protect the formyl group. As mentioned above, the hydroxyl groups of both the $5^{\prime}$ and $3^{\prime}$ ends of DNA can be oxidized by $\mathrm{KRuO}_{4}$ which can induce labeling of non-5hmC containing DNA with azi-BP. Second, the mixture was ligated with a modified adapter and then oxidized by $\mathrm{KRuO}_{4}$. Third, the mixed system was incubated with azi-BP and DBCO-S-S-PEG3biotin. Finally, the purified ODNs were obtained for affinity enrichment using streptavidin-coated magnetic beads. The enrichment efficiency was calculated using qPCR. 5hmC-DNA was enriched 297 -fold more than non-modified C-DNA (Fig. $6 \mathrm{~b}$ and $\mathrm{S} 4 \dagger$ ). A similar level of enrichment was observed for $5 \mathrm{hmC}$-DNA compared to $5 \mathrm{fC}-\mathrm{DNA}$, indicating that $5 \mathrm{fC}$ protected by hydroxylamine could not be captured. The results of enrichment analysis and Illumina sequencing revealed that our strategy can be used as a potential strategy for the single-base resolution analysis of $5 \mathrm{hmC}$ in the whole genome without bisulfite treatment.

\section{Conclusions}

In summary, we demonstrated a new method to detect and sequence $5 \mathrm{hmC}$ at single-base resolution by chemical-mediated mismatching. The Sanger sequencing and Illumina sequencing analyses clearly identified $5 \mathrm{hmC}$ through C-to-T conversion. We were able to detect the 5 hmC signal from mESC genomic DNA. The reactivity inhibition of DNA polymerase caused by the 
labeled $5 \mathrm{hmC}$ can enable quick screening of existing $5 \mathrm{hmC}$. A pull-down analysis indicated that our strategy can selectively enrich fragments containing $5 \mathrm{hmC}$ in DNA. During the revision of this study, a bisulfite-free method that detects $5 \mathrm{hmC}$ in hESCs and cfDNA has been reported. ${ }^{41}$ The main advantage of this method is that it is bisulfite-free, yet has a single-base resolution nature. However, the condition of oxidation that we use is harsh. Further efforts should be made to improve this strategy. In general, our findings can provide an alternative for the whole-genome mapping of epigenetic modifications.

\section{Methods}

\section{Synthesis of 80 bp ODN-hmC and ODN-fC by polymerase chain reaction}

To synthesize $5 \mathrm{hmC} / 5 \mathrm{fC}$ containing oligodeoxynucleotides, modified nucleotides were incorporated into the PCR. $80 \mathrm{bp}$ ds ODN-hmC (E-DNA-hmC) (see Table S1†) was synthesized using template 2 , forward primer 2 and reverse primer 2 in the presence of dATP, dTTP, dGTP and dhmCTP. $80 \mathrm{bp}$ ds ODN-fC (E-DNA-hmC) (see Table S1†) was synthesized using template 3 , forward primer 3 and reverse primer 3 in the presence of dATP, dTTP, dGTP and dfCTP. PCR reactions were prepared with $10 \times$ DreamTaq buffer $(5 \mu \mathrm{L}), 2 \mu \mathrm{L}$ forward primer $(10 \mu \mathrm{M})$, $2 \mu \mathrm{L}$ reverse primer $(10 \mu \mathrm{M}), 1 \mu \mathrm{L}$ template $(100 \mathrm{nM}), 1 \mu \mathrm{L}$ dATP (10 mM), $1 \mu \mathrm{L}$ dTTP (10 mM), $1 \mu \mathrm{L}$ dGTP $(10 \mathrm{mM}), 1 \mu \mathrm{L}$ dXTP (X $=$ hmC or fC) $(10 \mathrm{mM}), 5 \mathrm{U}$ DreamTaq polymerase and $\mathrm{ddH}_{2} \mathrm{O}$ to give a final volume of $50 \mu \mathrm{L}$. The mixture was then subjected to the following thermal cycle: $95{ }^{\circ} \mathrm{C}$ for $3 \mathrm{~min}$, 35 cycles of $95{ }^{\circ} \mathrm{C}$ for $10 \mathrm{~s}, 60{ }^{\circ} \mathrm{C}$ for $30 \mathrm{~s}$, and $72{ }^{\circ} \mathrm{C}$ for $90 \mathrm{~s}$, and $72{ }^{\circ} \mathrm{C}$ for 3 min using a $100^{\mathrm{TM}}$ Thermal Cycler (BioRad). The PCR product was purified using a DNA Clean \& Concentrator $^{\mathrm{TM}}-5$ kit according to the manufacturer's instructions. The PCR product was confirmed by $4 \%$ agarose gel electrophoresis (AGE) analysis (Fig. S3 $\uparrow$ ). The DNA concentration was quantified using a NanoDrop 2000c (Thermo Scientific, USA).

\section{Hydroxylamine protection of $5 \mathrm{fC}$}

To prevent $5 \mathrm{fC}$ from reacting with azi-BP, we use hydroxylamine to protect $5 \mathrm{fC}$. The hydroxylamine protection of $5 \mathrm{fC}$ was performed in $100 \mathrm{mM}$ MES buffer (pH 5.0), $10 \mathrm{mM}$ O-ethylhydroxylamine (in $\mathrm{ddH}_{2} \mathrm{O}$, Aldrich, 274992), and $2 \mu \mathrm{L}(100 \mu \mathrm{M})$ ODN-5fC or $200 \mathrm{ng} 80 \mathrm{bp}$ ds ODN-5fC for $2 \mathrm{~h}$ at $37^{\circ} \mathrm{C}$. The mixture was purified using Micro Bio-Spin ${ }^{\mathrm{TM}}$ P-6 Gel Columns in SSC buffer after being pre-washed with $\mathrm{ddH}_{2} \mathrm{O}(3 \times 500 \mu \mathrm{L})$ for removing $O$-ethylhydroxylamine and MES.

\section{Dot-blot assay}

For the dot-blot assay, different DNA strands were dotted on an Amersham Hybond- $\mathrm{N}^{+}$membrane (GE Healthcare). After drying, the dots were crosslinked with the membrane using UV light (254 nm) at RT for 5 min twice and washed with $1 \times$ TBST twice. Then the membrane was blocked with $5 \%$ BSA at $37{ }^{\circ} \mathrm{C}$ for $1 \mathrm{~h}$ and washed with $1 \times$ TBST five times. After labeling with streptavidin-HRP $(1: 1500)$ (Thermo Scientific) at $37^{\circ} \mathrm{C}$ for $1 \mathrm{~h}$ and washing with $1 \times$ TBST four times, the results were visualized by enhanced chemiluminescence (SuperSignal ${ }^{\mathrm{TM}}$ West Pico Chemiluminescent Substrate, Cat: 34077, Thermo Scientific) using a Molecular Imager ${ }^{\circledR}$ ChemiDocTM XRS+ Imaging System (Bio-Rad). Finally, the membrane was steeped in methylene blue (in NaOAc buffer) to verify the existence of DNA in every dot.

\section{The modified adapter solution for protecting hydroxyl groups at both the $5^{\prime}$ and $3^{\prime}$ ends of DNA}

The modified universal adapter is a $5^{\prime}$-O-methylated ODN with a sequence of $5^{\prime}$-MeO-AATGATACGGCGACCACCGAGATCTACAC TCTTTCCCTACACGACGCTCTTCCGATCT-3' (Takara Biotechnology, China) and a $3^{\prime}$-O-phosphorylated ODN with a sequence of 5'-GATCGGAAGAGCACACGTCTGAACTCCAGTCACNNNNNNATC TCGTATGCCGTCTTCTGCTTG-O-phosphate-3' (Sangon Biotech, China Aldrich), where NNNNNN corresponds to TruSeq (Illumina) barcoding, made up to a solution ( $25 \mu \mathrm{M}$ each) in $50 \mathrm{mM}$ $\mathrm{NaCl}$ and $20 \mathrm{mM}$ Tris- $\mathrm{HCl}(\mathrm{pH} 7)$ and annealed prior to use.

\section{Conflicts of interest}

There are no conflicts to declare.

\section{Acknowledgements}

We thank the National Natural Science Foundation of China (21432008, 91753201 and 21721005 to X. Z.) and the China Postdoctoral Innovative Talent Support Program of China (No. BX20180228 to Y. W.). The numerical calculations in this paper have been done on the supercomputing system in the Supercomputing Center of Wuhan University.

\section{Notes and references}

1 D. Han, X. Lu, A. H. Shih, J. Nie, Q. You, M. M. Xu, A. M. Melnick, R. L. Levine and C. He, Mol. Cell, 2016, 63, 711-719.

2 Y. Fu and C. He, Curr. Opin. Chem. Biol., 2012, 16, 516-524.

3 L. Shen and Y. Zhang, Curr. Opin. Cell Biol., 2013, 25, 289296.

4 Y. Chen, T. Hong, S. Wang, J. Mo, T. Tian and X. Zhou, Chem. Soc. Rev., 2017, 46, 2844-2872.

5 S. Ito, L. Shen, Q. Dai, S. C. Wu, L. B. Collins, J. A. Swenberg, C. He and Y. Zhang, Science, 2011, 333, 1300.

6 M. Tahiliani, K. P. Koh, Y. Shen, W. A. Pastor, H. Bandukwala, Y. Brudno, S. Agarwal, L. M. Iyer, D. R. Liu, L. Aravind and A. Rao, Science, 2009, 324, 930.

7 Y. Wang, C. Liu, T. Wang, T. Hong, H. Su, S. Yu, H. Song, S. Liu, X. Zhou, W. Mao and X. Zhou, Anal. Chem., 2016, 88, 3348-3353.

8 G. Ficz, M. R. Branco, S. Seisenberger, F. Santos, F. Krueger, T. A. Hore, C. J. Marques, S. Andrews and W. Reik, Nature, 2011, 473, 398.

9 S. Ito, A. C. D'Alessio, O. V. Taranova, K. Hong, L. C. Sowers and Y. Zhang, Nature, 2010, 466, 1129.

10 H. Stroud, S. Feng, S. Morey Kinney, S. Pradhan and S. E. Jacobsen, Genome Biol., 2011, 12, R54. 
11 K. E. Szulwach, X. Li, Y. Li, C.-X. Song, J. W. Han, S. Kim, S. Namburi, K. Hermetz, J. J. Kim, M. K. Rudd, Y.-S. Yoon, B. Ren, C. He and P. Jin, PLoS Genet., 2011, 7, e1002154.

12 S.-G. Jin, X. Wu, A. X. Li and G. P. Pfeifer, Nucleic Acids Res., 2011, 39, 5015-5024.

13 S. Kriaucionis and N. Heintz, Science, 2009, 324, 929.

14 K. E. Szulwach, X. Li, Y. Li, C.-X. Song, H. Wu, Q. Dai, H. Irier, A. K. Upadhyay, M. Gearing, A. I. Levey, A. Vasanthakumar, L. A. Godley, Q. Chang, X. Cheng, C. He and P. Jin, Nat. Neurosci., 2011, 14, 1607.

15 T. Wang, Q. Pan, L. Lin, K. E. Szulwach, C.-X. Song, C. He, H. Wu, S. T. Warren, P. Jin, R. Duan and X. Li, Hum. Mol. Genet., 2012, 21, 5500-5510.

16 V. Valinluck, H.-H. Tsai, D. K. Rogstad, A. Burdzy, A. Bird and L. C. Sowers, Nucleic Acids Res., 2004, 32, 4100-4108.

17 O. Yildirim, R. Li, J.-H. Hung, P. B. Chen, X. Dong, L.-S. Ee, Z. Weng, O. J. Rando and T. G. Fazzio, Cell, 2011, 147, 1498-1510.

18 J. A. Hackett, J. J. Zylicz and M. A. Surani, Trends Genet., 2012, 28, 164-174.

19 C. Quivoron, L. Couronné, V. Della Valle, C. K. Lopez, I. Plo, O. Wagner-Ballon, M. Do Cruzeiro, F. Delhommeau, B. Arnulf, M.-H. Stern, L. Godley, P. Opolon, H. Tilly, E. Solary, Y. Duffourd, P. Dessen, H. Merle-Beral, F. Nguyen-Khac, M. Fontenay, W. Vainchenker, C. Bastard, T. Mercher and O. A. Bernard, Cancer Cell, 2011, 20, 25-38.

20 K. Chen, J. Zhang, Z. Guo, Q. Ma, Z. Xu, Y. Zhou, Z. Xu, Z. Li, Y. Liu, X. Ye, X. Li, B. Yuan, Y. Ke, C. He, L. Zhou, J. Liu and W. Ci, Cell Res., 2015, 26, 103.

21 C. J. Mariani, J. Madzo, E. L. Moen, A. Yesilkanal and L. A. Godley, Cancers, 2013, 5, 786-814.

22 E. Kriukiene, Z. Liutkeviciute and S. Klimasauskas, Chem. Soc. Rev., 2012, 41, 6916-6930.

23 T. F. Kraus, D. Globisch, M. Wagner, S. Eigenbrod, D. Widmann, M. Munzel, M. Muller, T. Pfaffeneder, B. Hackner, W. Feiden, U. Schuller, T. Carell and H. A. Kretzschmar, Int. J. Cancer, 2012, 131, 1577-1590.

$24 \mathrm{H}$. Wu and Y. Zhang, Cell, 2014, 156, 45-68.

25 H. Wu, A. C. D'Alessio, S. Ito, Z. Wang, K. Cui, K. Zhao, Y. E. Sun and Y. Zhang, Genes Dev., 2011, 25, 679-684.

26 C.-X. Song, K. E. Szulwach, Y. Fu, Q. Dai, C. Yi, X. Li, Y. Li, C.-H. Chen, W. Zhang, X. Jian, J. Wang, L. Zhang,
T. J. Looney, B. Zhang, L. A. Godley, L. M. Hicks, B. T. Lahn, P. Jin and C. He, Nat. Biotechnol., 2010, 29, 68. 27 M. Yu, G. C. Hon, K. E. Szulwach, C.-X. Song, L. Zhang, A. Kim, X. Li, Q. Dai, Y. Shen, B. Park, J.-H. Min, P. Jin, B. Ren and C. He, Cell, 2012, 149, 1368-1380.

28 M. J. Booth, M. R. Branco, G. Ficz, D. Oxley, F. Krueger, W. Reik and S. Balasubramanian, Science, 2012, 336, 934.

29 G. Hayashi, K. Koyama, H. Shiota, A. Kamio, T. Umeda, G. Nagae, H. Aburatani and A. Okamoto, J. Am. Chem. Soc., 2016, 138, 14178-14181.

30 M. Münzel, L. Lercher, M. Müller and T. Carell, Nucleic Acids Res., 2010, 38, e192.

31 C. Zhu, Y. Gao, H. Guo, B. Xia, J. Song, X. Wu, H. Zeng, K. Kee, F. Tang and C. Yi, Cell Stem Cell, 2017, 20, 720-731. 32 B. Xia, D. Han, X. Lu, Z. Sun, A. Zhou, Q. Yin, H. Zeng, M. Liu, X. Jiang, W. Xie, C. He and C. Yi, Nat. Methods, 2015, 12, 1047.

33 C. Liu, Y. Wang, W. Yang, F. Wu, W. Zeng, Z. Chen, J. Huang, G. Zou, X. Zhang, S. Wang, X. Weng, Z. Wu, Y. Zhou and X. Zhou, Chem. Sci., 2017, 8, 7443-7447.

34 Y. Wang, C. Liu, X. Zhang, W. Yang, F. Wu, G. Zou, X. Weng and X. Zhou, Chem. Sci., 2018, 9, 3723-3728.

35 Y. Wang, C. Liu, W. Yang, G. Zou, X. Zhang, F. Wu, S. Yu, X. Luo and X. Zhou, Chem. Commun., 2018, 54, 1497-1500.

36 C.-X. Song, T. A. Clark, X.-Y. Lu, A. Kislyuk, Q. Dai, S. W. Turner, C. He and J. Korlach, Nat. Methods, 2011, 9, 75.

37 C.-X. Song, K. E. Szulwach, Q. Dai, Y. Fu, S.-Q. Mao, L. Lin, C. Street, Y. Li, M. Poidevin, H. Wu, J. Gao, P. Liu, L. Li, G.-L. Xu, P. Jin and C. He, Cell, 2013, 153, 678-691.

38 F. Kawasaki, D. Beraldi, R. E. Hardisty, G. R. McInroy, P. van Delft and S. Balasubramanian, Genome Biol., 2017, 18, 23.

39 C. Zhao, H. Wang, B. Zhao, C. Li, R. Yin, M. Song, B. Liu, Z. Liu and G. Jiang, Nucleic Acids Res., 2014, 42, e81.

40 F. Kawasaki, S. Martínez Cuesta, D. Beraldi, A. Mahtey, R. E. Hardisty, M. Carrington and S. Balasubramanian, Angew. Chem., 2018, 130, 9842-9844.

41 H. Zeng, B. He, B. Xia, B. A. I. Dongsheng, X. Lu, J. Cai, L. Chen, A. Zhou, C. Zhu, H. Meng, Y. Gao, H. Guo, C. He, Q. Dai and C. Yi, J. Am. Chem. Soc., 2018, DOI: 10.1021/ jacs.8b08297. 